\title{
Analysis of Pragmatic Ambivalence from the Perspective of Relevance Theory
}

\author{
Ruihong Huang \\ Teaching Center, Zhejiang Open University, Hangzhou, China \\ Email: 870534247@qq.com
}

How to cite this paper: Huang, R. H. (2021). Analysis of Pragmatic Ambivalence from the Perspective of Relevance Theory. Open Journal of Social Sciences, 9, 1-10. https://doi.org/10.4236/jss.2021.95001

Received: March 30, 2021

Accepted: May 3, 2021

Published: May 6, 2021

Copyright $\odot 2021$ by author(s) and Scientific Research Publishing Inc. This work is licensed under the Creative Commons Attribution International License (CC BY 4.0).

http://creativecommons.org/licenses/by/4.0/

\begin{abstract}
Pragmatic ambivalence refers to a linguistic phenomenon in which the communicator uses vague or ambiguous words to convey the illocutionary force to the other party in a specific context. It is an indispensable communicative strategy for successful communication in daily communication activities. Relevance theory can explain pragmatic ambivalence from three aspects: intentional relevance, contextual relevance and relevance reasoning. Therefore, relevance theory has strong explanatory power and applicability for pragmatic ambivalence as a communicative strategy. Using relevance theory to study pragmatic ambivalence is conducive to people's further understanding of pragmatic ambivalence as a linguistic phenomenon, and has a very positive significance for the research and development of ambivalence in pragmatics.
\end{abstract}

\section{Keywords}

Pragmatic Ambivalence, Relevance Theory, Illocutionary Force

\section{Introduction}

Relevance theory is a theory that interprets communicative activities from cognitive perspective. It was first proposed by Dan Sperber, a famous French linguist, and Deirdre Wilson, a British linguist, in their book About Relevance: Communication and Cognition, which was published in 1986 and revised in 1995. Its theoretical basis is Grice's Conversational Implicature Theory. As a successful theoretical mode, relevance theory has a very strong explanatory function for verbal communication activities. Therefore, relevance theory has been widely used in the field of linguistics and applied linguistics in recent years. As a communicative strategy, pragmatic ambiguity is also widely used in people's daily communication activities, which is an indispensable linguistic phenomenon for successful communication. This paper attempts to combine 
relevance theory with pragmatic ambivalence to explore pragmatic ambivalence as a communicative strategy from the perspective of relevance theory.

\section{Communicative and Cognitive Principles of Relevance Theory}

Relevance theory puts forward a new theoretical mode for the study of communication activities. It argues that the hearer will search for meaning in any given communication situation and having found meaning that fits their expectation of relevance will stop processing (Yang, 2019). Sperber and Wilson believe that discourse communication behavior in people's daily life is actually an ostensive-inferential process, which is closely related to two aspects, namely, information intention and communication intention. According to relevance theory, every ostensive-inferential communicative activity conveys some relevance hypotheses of communicators, and contextual effects and processing efforts play a decisive role in relevance. In the case that all other conditions and elements are the same, relevance theory holds that context effect and relevance are in direct proportion, but processing effort and relevance are in inverse proportion. By analyzing the theoretical framework of relevance theory, it can be inferred that relevance is a constant term, but context is changing and dynamic, so it is a variable term. Relevance theory is based on two interrelated principles: communicative principle and cognitive principle.

\subsection{Communicative Principles of Relevance Theory}

Among many theories that attempt to research and interpret communication activities, Sperber \& Wilson's relevance theory is undoubtedly one of the most successful modes so far. Relevance theory focuses on human communication and discourse understanding (Li, 2019), it holds that the process of verbal communication between the two parties is a process of meaning understanding. In fact, communication is a cognitive activity conducted by both parties. Therefore, the expression of language and the understanding of word meaning and discourse of the communicators in the process of communication should be related to the cognitive context at that time and finally achieve mutual manifestness, which is the communicative principle of relevance theory. The cognitive context here refers to the surrounding world in which the two sides of verbal communication get along with each other, while the mutual reflection shows that both sides of verbal communication understand and clearly understand the topic or a fact they are talking with. Therefore, the main condition for effective and smooth communication is the understanding of the cognitive context of coexistence between the two sides of verbal communication.

In the process of communication, the greater the cognitive context in which the two sides of verbal communication get along, the greater the probability that the two sides of communication may achieve mutual manifestness, and the more likely they are to achieve the most effective communication effect. In fact, the 
factors that affect the cognitive context of both sides of communication mainly refer to the objective factors related to the communicative situation and the subjective factors related to the psychological activities of the communicators. Generally speaking, the two sides of communication can perceive the objective factors related to the communication situation, but the cognition of the communication situation is likely to be inconsistent. The difference of cognition is reflected in the different time, rank and order of the two parties in the process of communication. Therefore, the degree of manifestness is also different because of the different situations. However, the mutual manifestness does exist objectively during speech communication. Now the question is, in the process of manifestness, what criteria are used to process information? In other words, what are the criteria for the understanding of communicative discourse?

\subsection{Cognitive Principles of Relevance Theory}

For the above questions, relevance theory explains that the criteria for the processing of information or the understanding of communicative discourse are based on the cognitive principles of human cognition, that is to say, human cognition is always combined with the maximum relevance, but in real communication, both parties only hope to achieve optimal relevance. Any ostensive verbal communication shows that this kind of communication has the optimal relevance (Sperber \& Wilson, 1995).

Sperber \& Wilson explain the optimal relevance as follows:

1) There should be a great deal of relevance in the ostensive speech communication activities, which makes the hearer think it is worthwhile to make some efforts to deal with and process them.

2) There are some similarities between the ostensive verbal communication activities and preferences of the communicators, so they have the maximum relevance.

In fact, the maximum relevance refers to the fact that the efforts made by both parties in the process of communication may be the smallest, but the communication effect achieved may be the largest, while the optimal relevance refers to the fact that both parties in the process of communication have made very effective efforts to understand the discourse and achieved excellent communication effect. In the process of verbal communication, both sides of communication should first choose some useful context information and code information, and then adjust their Communicative discourse in time to adapt to the communication activities, so as to enrich and broaden the cognitive context of both sides in the communication process, so that the communication activities can be carried out smoothly, both sides of the communication can reach mutual understanding.

Relevance theory has the characteristics of diversity. It absorbs and adopts the relevant research results of behavioral science, psychology and cognitive science, which is conducive to the interpretation and research of communication activi- 
ties and behaviors in the process of communication. Therefore, it is more convincing than other communication theories. As a common communicative strategy in people's daily communication, does pragmatic ambivalence still have the same strong explanatory power? If the answer is affirmative and clear, how does relevance theory explain the pragmatic ambivalence? Before in-depth analysis and discussion of this question, let's first analyze the pragmatic ambivalence as a communicative strategy.

\section{The Definition and Function of Pragmatic Ambivalence}

\subsection{The Definition of Pragmatic Ambivalence: Illocutionary Force}

The theory of ambivalence was first put forward by Professor Zadeh, a famous American system scientist, in 1965. At present, the study of ambivalence language has involved all aspects of language research. For the definition of pragmatic ambivalence, Thomas (1995) holds that pragmatic ambivalence refers to a special linguistic phenomenon in which the speaker conveys several kinds of illocutionary forces or illocutionary behaviors to the addressee at the same time through the use of unclear or vague communication language in a specific context during the process of communication between the two parties.

According to the Speech Act Theory of Austin, a British language philosopher, there are generally three different speech acts in the process of communication, namely, locutionary act, illocutionary act and perlocutionary act. Locutionary act or speech act is simply to utter words, that is, the speaker's speech act itself. Although speech behavior does not promote the occurrence of verbal communication behavior, but this kind of speech behavior through the expression of greetings, sending information, giving instructions and other ways to achieve illocutionary act, and the communicator expressed the same intention. In this process, communicators also achieve perlocutionary act, that is, to achieve the effect of communication. Therefore, the main problem in the study of language communication is how the communicators use language to convey their communicative intention and how to correctly understand each other's communicative intention. Pragmatic ambivalence refers to the vague or ambiguous utterances used by the communicators in a specific context to convey the illocutionary force to the other party (He, 2001). For example, would you like to come in and sit down? This sentence expresses a variety of different illocutionary behaviors such as invitation, request or order, so its boundary is uncertain and vague. There are three types of pragmatic ambivalence.

The first is pragmatic bivalence/plurivalence, which mainly refers to the linguistic phenomenon that a certain utterance of the communicator conveys two or more illocutionary forces to the same addressee in the process of communication. Sometimes these illocutionary forces may be completely different.

The second is pragmatic multivalence, which mainly refers to the linguistic phenomenon that a certain utterance of the communicator transmits various illocutionary forces to different listeners in the process of communication. 
The third is conditional bivalent illocutionary act, which mainly refers to the linguistic phenomenon that a certain utterance of the communicator can transmit another illocutionary force as long as the expressed conditions are feasible in the process of communication (He, 2000).

\subsection{The Pragmatic Function of Pragmatic Ambivalence: Communicative Strategies}

Leech (1983), a famous British linguist, also believes that pragmatic ambivalence is a complex and diverse phenomenon of illocutionary behavior. The concrete manifestation of its vagueness is the uncertainty of illocutionary behavior or the illocutionary force of communicative discourse in the process of communication. As a communicative strategy, pragmatic ambivalence is deliberately used by the communicator, with clear motivation and purpose, and considering the common interests of both sides in communication, the speaker consciously and purposefully uses unclear words, mainly to let the addressee bear some responsibilities for the possible consequences of vague language, so that he can take the initiative in communication and move forward and backward freely (Channel, 2000). The purpose of intentional use of pragmatic ambivalence by communicators is to achieve certain communicative goals and achieve the following pragmatic functions, such as:

1) The function of adjustment in communication: communicators use pragmatic ambivalence to adjust the possible conflicts between the two sides of communication.

2) The function of humor in communication: communicators use pragmatic ambivalence to create a relaxed and humorous communication atmosphere to ensure smooth communication.

3) The function of infection in communication: the purpose of communication can be achieved by strengthening the infection of communication language and enhancing the communicative effect of language.

4) The function of politeness in communication: pragmatic ambivalence is used because of politeness consideration or consideration of the face of the other party in communication.

5) The function of implication in communication: the illocutionary force is transmitted by implication in the process of communication.

In a word, the purpose of pragmatic ambivalence is often due to various considerations beyond communicative discourse. Therefore, pragmatic ambivalence is not only a linguistic phenomenon in daily communication activities, but more often it is used skillfully by communicators as a special communicative strategy (Li, 2007).

\section{The Explanatory Power of Relevance Theory to Pragmatic Ambivalence}

According to the relevance theory, the criterion of whether a communicative activity can be carried out smoothly and effectively is the mutual reflection of cog- 
nitive context between the two parties. However, in the process of communication, the cognitive context of the two parties cannot be the same, and the cognitive abilities of the two parties are also different, which makes the information of the cognitive context in the process of communication may be different to the degree of reflection of the two parties, which will lead to the speaker and the addressee's uncertain interpretation of the same language, and ultimately produce the pragmatic ambivalence as a unique linguistic phenomenon. Therefore, relevance theory has strong explanatory power and wide applicability to the pragmatic ambivalence in the communication process.

The relevance theory holds that communicators tend to find the optimal relevance, that is, to find a certain context to achieve the balance between effect and input, to achieve the maximum contextual effect through the minimum efforts, and finally to obtain the most relevant communication information. In the process of communication, from the projection of communicative intention to meaning, communicative language is the carrier and tool of transmitting communicative information. The communicative information it carries may be smaller or larger than the preset meaning of the speaker, which will produce the derivative meaning, and eventually lead to the generation of pragmatic ambivalence. According to relevance theory, in the process of understanding the speaker's language, the addressee first assumes that there is a certain relevance between the communicative language and the communicative intention as well as the context, and then through relevance principle and context reasoning to increase or reduce the communicative language to achieve the best understanding.

\subsection{The First Interpretation of Relevance Theory to Pragmatic Ambivalence: Intentional Relevance}

Sperber and Wilson think that the two parties in communication generally follow the principle of relevance when they try to understand the communicative discourse. So, as a special communicative strategy, does pragmatic ambivalence also follow the principle of relevance? Pragmatic ambivalence is a general term for all the uncertain features in communication, and the pragmatic ambivalence produced in the process of communication is not all against the communicative intention of the communicator. Sometimes the speaker is driven by communicative intention, and uses pragmatic ambivalence in a specific context, such as purposefully violating the relationship between communicative language and communicative intention, to indirectly express the illocutionary force to achieve the desired communicative effect. The typical expression of this kind of communication is some indirect language behaviors and pragmatic vagueness phenomenon produced by the communicators in the process of communication. Therefore, it can be considered that this kind of communication behavior is the intention-related communication activity through the communication discourse as the communication carrier and tool. Let's see the following dialogue:

\section{Example 1:}

Man: Would you like to go to the beach with me? 
Woman: It's raining.

Due to the different context in the process of communication, in this very simple dialogue between a man and a woman, we can have different understanding and interpretation of the communicative intention of the communicators. If the man and the woman in the conversation have a good feeling for each other, the woman likes to go to the beach with the men. For the invitation of the man, the woman answers "it's raining", showing their communicative intention including complaining about the rainy day and a very sorry mood that they can't go to the beach together. If the woman doesn't like to be with the man and doesn't want to accept the man's invitation to go to the beach, but considering that face-to-face rejection would make the man lose face, the woman deliberately uses "it's raining" to convey the communicative intention of euphemism rejection. In the process of communication, this kind of pragmatic ambivalence makes discourse communication achieve polite and implicit communicative effect. In fact, this dialogue uses pragmatic ambivalence as a special communicative strategy, in which the communicative discourse of the two parties only plays a role of symbol or tool.

Sperber \& Wilson also believe that the use of language symbols or the process of language communication is actually the process of phenomenon generation and interpretation. The function of language symbols in communication is mainly to provide some information direction, and at the same time, it helps to regulate the mutual cognitive context of both sides of communication, so as to produce some similarities between the psychological representations (understandings) of both sides of communication, and finally bring the expected communicative effect. It can be concluded that the verbal communication activities that the communicators carry out in the process of communication are in fact intended communication activities, while pragmatic vagueness achieves the intended communicative purpose by using this feature of verbal communication.

\subsection{The Second Interpretation of Relevance Theory to Pragmatic Ambivalence: Contextual Relevance}

As the core theory of cognitive pragmatics, relevance theory promotes the "context" of the main research object of traditional pragmatics from the perspective of cognitive science and psychology, and explains the concept of "cognitive context" for the first time. According to relevance theory, cognitive context is actually a psychological structure, which processes human cognition of the objective world through long-term accumulated experience or thinking into a set in human brain, thus reflecting various subjective and objective relations between human and the objective world. In people's cognitive system, cognitive context is relatively stable, but at the same time, it is also dynamic, which is the basis of various pragmatic reasoning in the process of communication. Look at the following conversation.

\section{Example 2}

Father: Have you finished your homework and brushed your teeth? 
Daughter: I have done my homework.

In this dialogue, the father asks the daughter two questions, whether she has finished the homework and brushed her teeth, but the daughter only answers one of them, which makes the information asymmetry of the two sides in communication, and this asymmetry in the communication process leads to the generation of pragmatic ambiguity. Grice (1975) holds that the quantity criterion of cooperative principle should be followed in the process of communication, that is to say, the amount of discourse information provided by both parties in communication should be basically the same, neither too much nor too little. Because if the amount of discourse information provided by the speaker is too much or too little, it may lead to the misunderstanding of the addressee and even the misunderstanding of both sides. At that time, the communicators should combine with the specific context, mobilize their cognitive system, and use relevance theory to get the true meaning of communicative discourse. In the above conversation, actually, the daughter intentionally doesn't answer the father's question about brushing her teeth. Through contextual relevance, we can tell that the daughter hasn't brushed her teeth.

Therefore, the final communicative effect of the two parties does not lie in the amount of communicative words, and the contextual relevance plays a greater role in the process of communication. The emergence of pragmatic ambivalence in the process of communication is conducive to better regulating the cognitive context of both sides of communication, making the context effect to a greater extent, and ultimately conducive to the increase of the richness and dynamism of communication.

\subsection{The Third Interpretation of Relevance Theory to Pragmatic Ambivalence: Relevance Reasoning}

According to Sperber \& Wilson's relevance theory, both sides of communication try to make as little effort as possible to get as much communication effect as possible. In the process of communication, the emergence of pragmatic vagueness is mainly due to the fact that the communicators make full use of the principle of relevance. In fact, both sides of communication can establish relevance in the process of reasoning by making up for the lack of communication information and reasoning correction, which makes the communicative intention of the communicator fully reflected. Look at the following conversation:

\section{Example 3}

Husband: I'm tired.

Wife: I'll make the meal.

This is a very simple dialogue. From the perspective of communication intention, it is likely that there is pragmatic ambiguity in the husband's words. When it comes to cooking time, a sentence "I am tired" conveys the meaning of politeness, request, statement, etc. And the context in the communication process is a variable. If there is not enough context information, the husband's words can also have several kinds of contextual interpretations, such as he is so tired that he 
doesn't want to talk, doesn't want to do housework, wants to take a bath first, wants to have a little rest, etc. It can be seen from the dialogue that the wife's understanding is that "the husband politely expresses that he does not want to cook or do housework". In order to establish a connection between the wife's answer and the husband's words, we should use relevance reasoning, and the specific reasoning process includes the following steps:

Pl: Meal is not ready. And there should be someone to make it.

P2: There are only husband and wife in the house who can make meals.

P3: So either husband or wife will make the meal.

P4: But husband is tired, that means husband will not make the meal.

P5: So wife is the only one available to make it. Otherwise, she is not cooperative.

The purpose of reasoning a simple dialogue in such a detailed way and decomposing the steps is to show that the process of relevance reasoning is actually an effort process to find the best balance between the information processing cost and the communication effect of the communication discourse, which is also a process to find the best relevance between the communication discourse and the context.

\section{Conclusion}

Through the analysis of some specific examples, this paper discusses the special communicative strategy of pragmatic ambivalence in the process of communication from the perspective of relevance theory. Relevance theory is helpful for the addressee to acquire the relevance between the utterances by expanding cognitive context according to the explicit information of the utterances of the addresser, and finally to understand the real communicative intention contained in the vague or uncertain illocutionary force of the addresser, so as to realize the intentional communication between the two parties in the process of communication. Using relevance theory to study pragmatic ambivalence is conducive to people's further understanding of pragmatic ambivalence as a linguistic phenomenon, and has a very positive significance for the research and development of ambivalence in pragmatics.

\section{Acknowledgements}

My thanks to the anonymous reviewers for reading and commenting on the early drafts of this article.

\section{Funding}

The project is supported by the Paradigm Establishment of Curriculum Construction in Open University (Grant No. jg20191071), the Second Batch of Teaching Reform Research Projects in "the 13th Five-Year Plan" of Higher Education in Zhejiang Province. Huang Ruihong Excellent Teacher Studio of Applied English of Zhejiang Open University. Innovation Research Team of Eng- 
lish Teaching Paradigm of Zhejiang Open University in 2019.

\section{Conflicts of Interest}

The author declares no conflicts of interest regarding the publication of this paper.

\section{References}

Channel, J. (2000). Vague Language (pp. 31-43). Shanghai: Shanghai Foreign Language Education Press.

Grice, H. P. (1975). Syntax and Semantics 3: Speech Acts (pp. 75-79). New York: Academic Press.

He, Z. R. (2001). A Survey of Pragmatics (p. 32). Changsha: Hunan Education Publishing House.

He, Z. X. (2000). A New Introduction to Pragmatics (pp. 330-336). Shanghai: Shanghai Foreign Language Education Press.

Leech, D. H. (1983). Principle of Pragmatics (pp. 83-88). London: Longman.

Li, S. (2019). The Application of Relevance Translation Theory in Translation Teaching. Journal of Hubei Open Vocational College, No. 23, 168-169.

Li, Y. S. (2007). A Cognitive Approach to Pragmatic Vagueness. Journal of Huazhong University of Science and Technology (Social Science Edition), No. 1, 44-48.

Sperber, D., \& Wilson, D. (1995). Relevance: Communication \& Cognition (2nd ed., pp. 158-165). Oxford: Blackwell.

Thomas, J. A. (1995). Meaning in Interaction: An Introduction to Pragmatics (p. 195). London: Longman.

Yang, L. (2019). Relevance Theory in Translation of Film Subtitle. Overseas English, No. $11,175-176$. 